\title{
Pengembangan Usaha Produk Intelektual Kampus UPGRIS Farm
}

\author{
Ary Susatyo Nugroho, Endah Rita Sulistya Dewi, Eko Retno Mulyaningrum \\ FPMIPATI Universitas PGRI Semarang \\ arysusatyon@gmail.com
}

Key word:

Hydroponic, aquaculture, Agro-

edutourism

Kata Kunci

Hidroponik, aquakultur, Agroeduwisata

\section{Abstract}

UPGRIS-Farm is one business unit owned by PGRI University Semarang (UPGRIS) engaged in agriculture and fisheries. UPGRISFarm has been running for about five years and has produced some fresh vegetables and freshwater fish. Through the PPUPIK program, UPGRIS-Farm will be developed into an environmentally-friendly integrated agriculture based business unit, and produces fresh organic vegetables and fresh freshwater fish that are free and insecticide free to meet the needs of the community, both around the campus of UPGRIS and the people of Semarang. UPGRIS-Farm PPUPIK products will be generated through the merger of two technologies, namely "Hydroponic and Aquaculture" technology. UPGRIS's Devotional Team, which has expertise and experience in line with agriculture and plumbing, has also developed this business into an Agroedutourism for learners at the play group, early childhood and elementary level. Agroedutourism will combine the attractions of agriculture and fisheries with hydroponic and aquaculture technology and nature-based tourism that is clean, comfortable, and beautiful.

\section{Abstrak}

UPGRIS-Farm adalah salah satu unit bisnis milik Universitas PGRI Semarang (UPGRIS) yang bergerak di bidang pertanian dan perikanan. UPGRIS-Farm telah beroperasi selama sekitar lima tahun dan telah menghasilkan beberapa sayuran segar dan ikan air tawar. Melalui program PPUPIK, UPGRIS-Farm akan dikembangkan menjadi unit bisnis berbasis pertanian terintegrasi ramah lingkungan, dan menghasilkan sayuran organik segar dan ikan air tawar segar yang bebas dan bebas insektisida untuk memenuhi kebutuhan masyarakat, baik di sekitar kampus UPGRIS dan masyarakat Semarang. Produk-produk PPUPIK Pertanian UPGRIS akan dihasilkan melalui penggabungan dua teknologi, yaitu teknologi "Hidroponik dan Akuakultur". Tim Renungan UPGRIS, yang memiliki keahlian dan pengalaman yang sejalan dengan pertanian dan pemipaan, juga telah mengembangkan bisnis ini menjadi Agroeduwisata untuk pelajar di kelompok permainan, anak usia dini dan tingkat dasar. Agroeduwisata akan menggabungkan atraksi pertanian dan perikanan dengan teknologi hidroponik dan akuakultur dan pariwisata berbasis alam yang bersih, nyaman, dan indah. 


\section{PENDAHULUAN}

UPGRIS-Farm merupakan salah satu unit usaha yang dimiliki oleh Universitas PGRI Semarang (UPGRIS). Unit usaha ini bergerak di bidang pertanian dan perikanan dengan memanfaatkan lahan yang berada di Kampus III Jalan Pawiyatan Luhur III Nomor 1 Bendan Duwur Kota Semarang. UPGRIS-Farm telah berjalan kurang lebih lima tahun dan telah menghasilkan beberapa jenis sayuran dan ikan air tawar segar. Pangsa pasar produk UPGRIS-Farm sangat luas, mulai dari dosen dan karyawan UPGRIS, masyarakat di sekitar kampus, usaha catering, usaha cave, Pujasera, dan lain sebagainya. Akan tetapi, sayuran dan ikan segar yang dihasilkan masih terbatas jumlahnya, sehingga belum dapat memenuhi permintaan pasar. Produk UPGRIS-Farm baru dapat memenuhi permintaan masyarakat di sekitar kampus UPGRIS, belum dapat memenuhi permintaan masyarakat luas. Hal ini disebabkan karena pengelolaan UPGRIS-Farm belum maksimal, sehingga UPGRIS-Farm perlu dikembangkan lagi

Melalui program PPUPIK, UPGRISFarm juga dikembangkan mejadi unit usaha berbasis pertanian terpadu yang ramah lingkungan, dan menghasilkan produk sayuran organik dan ikan air tawar segar yang sehat dan bebas insektisida. Sayuran dan ikan air tawar diproduksi secara terpadu dalam sistem aquaponik, dan dilakukan di dalam green house. Dengan sistem aquaponik dan di dalam green house, maka produk sayuran menjadi lebih sehat karena bersifat organik dan bebas insektisida. Produksi sayuran dan ikan segar dan sehat ini diharapkan dapat memenuhi kebutuhan masyarakat, baik masyarakat di sekitar kampus UPGRIS maupun masyarakat Semarang secara luas.

Unit usaha PPUPIK UPGRIS-Farm dikembangkan lagi dengan membuka jenis usaha baru, yaitu Agroeduwisata. Agroeduwisata akan memadukan atraksi pertanian dan perikanan dengan teknik hidroponic dan aquaculture, Pendidikan dan Pelatihan hidroponic dan aquaculture, serta wisata alam berbasis lingkungan yang bersih, nyaman, dan asri. Dengan berkembangnya UPGRIS-Farm, diharapkan dapat menambah pemasukan bagi Universitas PGRI Semarang, serta lebih menggairahkan unit usaha PPUPIK UPGRIS-Farm.

\section{METODE PEMECAHAN MASALAH}

Terkait dengan permasalahan yang ada yaitu pengelolaan UPGRIS-Farm belum maksimal, dan pengembangan di bidang eduwisata, maka metodae pemecahan masalah yang dikemukakan 
adalah memaksimalkan kepakaran dan pengalaman dosen UPGRIS yang sejalan dengan bidang usaha UPGRIS-Farm. Beberapa dosen memiliki kemampuan dan pengalaman dalam penelitian maupun pengabdian tentang teknologi "hidroponik dan aquaculture". Intelektualitas dosen kali ini akan diwujudkan dalam bentuk PPUPIK untuk memaksimalkan pengelolaan unit usaha UPGRIS-Farm yang sudah ada.

UPGRIS-Farm dikelola melalui program PPUPIK oleh kelompok dosen di bawah Laboratorium Biologi Dasar Program Studi Pedidikan Biologi FPMIPATI Universitas PGRI Semarang. PPUPIK UPGRIS-Farm secara langsung berada di bawah koordinasi Dekan FPMIPATI dan Ketua Program Studi Pendidikan Biologi. Adapun penanggung jawab operasional adalah Direktur PPUPIK UPGRIS-Farm. Proses produksi sayuran dan ikan air tawar segar berkualitas berada di bawah tanggung jawab Manajer Produksi yang dibantu oleh Staf Ahli Pertanian, Staf Ahli Perikanan, dan tenaga lapangan. Sedangkan proses pemasaran produk PPUPIK UPGRIS-Farm berada di bawah tanggung jawab Manajer Pemasaran yang membawahi tenaga pemasaran. Adapun pembukuan akuntansi dan perpajakan dilaksanakan oleh bagian administrasi dan keuangan. Audit internal akan dilakukan secara kontinue oleh Tim Audit yang dibentuk oleh Rektor.

\section{HASIL DAN PEMBAHASAN}

Saat ini budidaya hidroponik dan sejenisnya sangat diminati masyarakat termasuk di kalangan sekolah, Teknologi hidroponic $a$ dalah teknologi pertanian modern dengan sistem penanaman tanpa tanah (Genuncio. 2012).Teknologi ini telah banyak dikembangkan oleh Program Studi Pendidikan Biologi UPGRIS yang sumber daya manusianya memiliki dasar ilmu teori dan terapan Botani, Agronomi, Hortikultura, Ekologi, dan Zoologi,

Demikian pula teknologi Aquaculture merupakan teknologi perikanan modern (Ekasari, 2009), yang telah dikembangkan pula di Program Studi Pendidikan Biologi. Teknologi "Hidroponic dan Aquaculture" merupakan dua teknologi yang akan digabung menjadi satu untuk menghasilkan Produk PPUPIK UPGRIS-Farm. Teknologi "Hidroponic dan Aquaculture" juga menjadi daya tarik dan bagian dari pengembangan Agroeduwisata UPGRISFarm.

Agroeduwisata adalah kegiatan wisata untuk tujuan studi yang dapat memberi pengetahuan dan pengalaman tentang alam pertanian melalui ilmu \& ilmu pertanian dalam arti luas yang mencakup pertanian bercocok tanam, peternakan, perikanan, kehutanan, baik 
di dalam maupun di luar lapang (Riyani, 2005 dalam Iren, 2007). Selanjutnya menurut Nurisjah (2001), dalam Budiarti dkk (2013), agrowisata didefinisikan sebagai rangkaian aktivitas perjalanan wisata yang memanfaatkan lokasi atau sektor pertanian mulai dari awal produksi hingga diperoleh produk pertanian dalam berbagai sistem dan skala dengan tujuan memperluas pengetahuan, pemahaman, pengalaman dan rekreasi di bidang pertanian.

Kegiatan wisata berbasis edukasi ini telah dilakukan dengan menerima kunjungan anak-anak peserta didik dari Kelompok Bermain dan TK Beetle Bug Semarang., program Agroeduwisata ini bukan hanya menjadi program rekreasi saja namun program ini mendekatkan pembelajaran pertanian bagi anak-anak sekolah. Tidak sekedar menanam sayuran, tetapi para peserta didik juga diajarkan bagaimana mengolah komoditi tersebut menjadi sesuatu yang bisa mereka konsumsi, secara sederhana namun mudah dipahami anak-anak.

Teknik hidroponik diperkenalkan dalam kegiatan ini. menjadi bentuk pengenalan pertanian usia dini, sehingga peserta didik dapat menghargai proses bertani untuk mendapatkan makanan yang biasa dimakan sehari-hari. Dan dapat menjadi jalan menumbuhkan rasa cinta pertanian sekaligus menjadi titik awal membuka cita-cita menjadi petani (modern).

Percobaan yang dilakukan anak-anak dimulai dengan memperkenalkan perangkat yang digunakan dalam teknologi hidroponik, mencoba untuk mempersiapkan netpot sebagai tempat tanaman, menanam benih dalam rockwool hingga memanen sayuran dalam instalasi hidroponik.

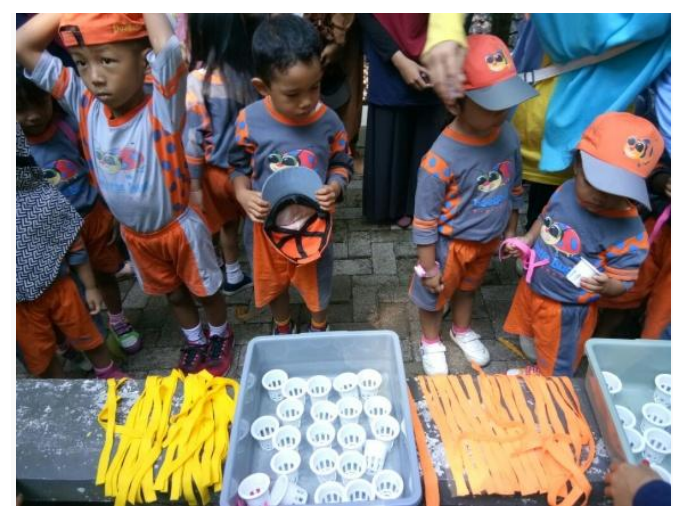

Gambar 1. Pengenalan Perangkat Hidroponik

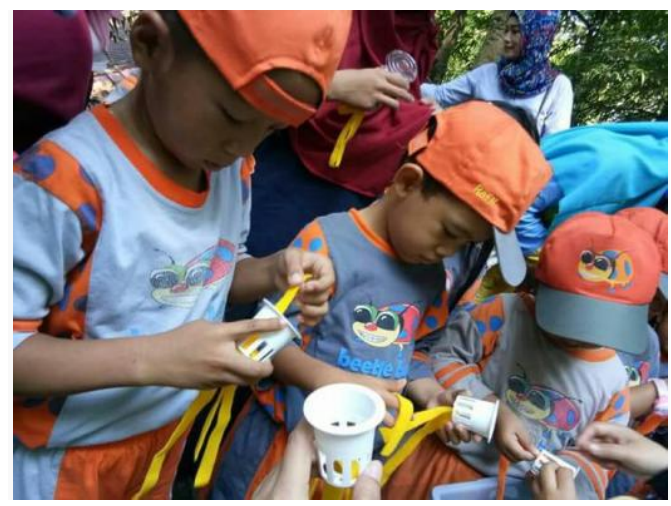

Gambar 2. Pemasangan Kain Flanel dalam Netpot 


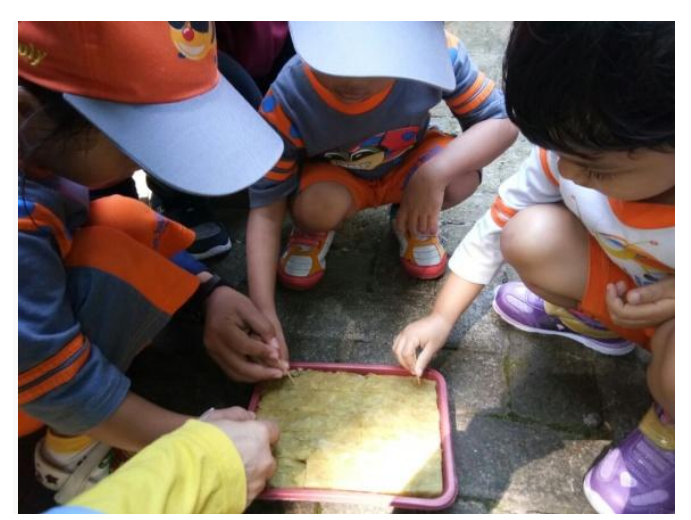

Gambar 3. Pemberian Benih dalam Rockwool

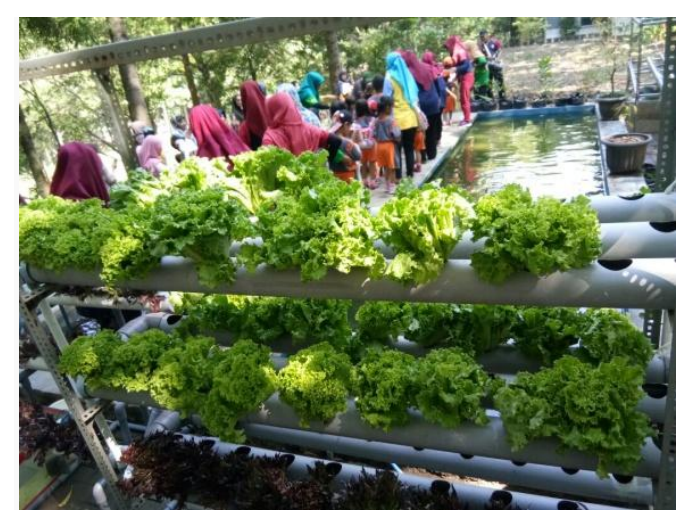

Gambar 4. Instalasi Hidroponik

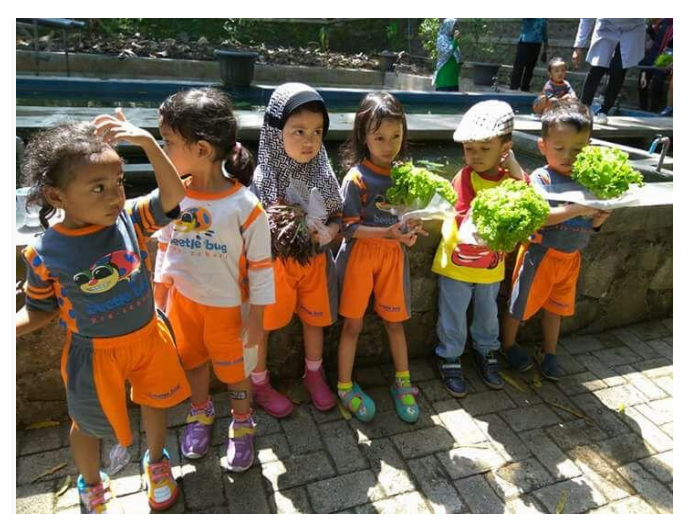

Gambar 5. Hasil Memanen Sayur Selada

Pengenalan pemeliharaan ikan dilakukan di kolam dalam green house maupun kolam di luar green house. Pemeliharaan di kolam dalam green house lebih ditikberatkan pada pengenalan berbagai jenis ikan hias. Sedangkan pengenalan pemeliharaan ikan di kolam di luar green house lebih pada cara budidaya ikan. Adapun ikan yang dibudidayakan adalah jenis ikan nila dan lele. Pengembangan Aquaculture yang akan digunakan dalam simtem perikanan ini adalah aquaculture Bioflok.

Seiring dengan perkembangan teknologi melalui pendekatan biologis, telah diterapkan teknologi bioflok untuk menjaga kualitas perairan budi daya. Teknologi bioflok merupakan teknologi penggunaan bakteri baik heterotrof maupun autotrof yang dapat mengkonversi limbah organik secara intensif menjadi kumpulan mikroorganisme yang berbentuk flok, kemudian dapat dimanfaatkan oleh ikan sebagai sumber makanan (de Schryver \& Verstraete 2009; Avnimelech 2012; Adharani at al, 2016)

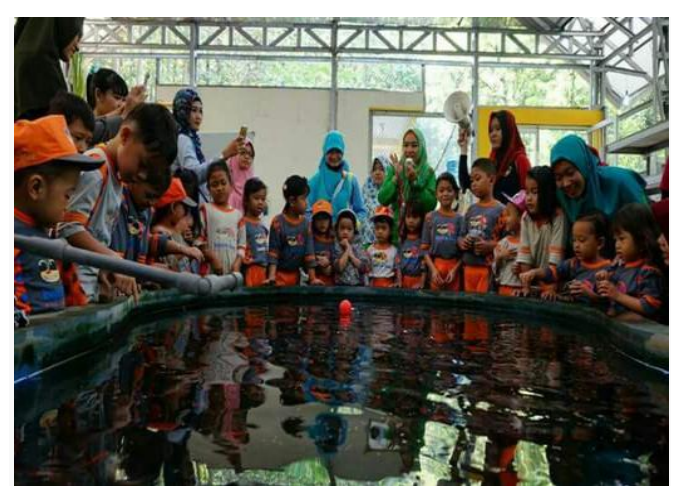

Gambar 6. Pengenalan Pemeliharaan Ikan 


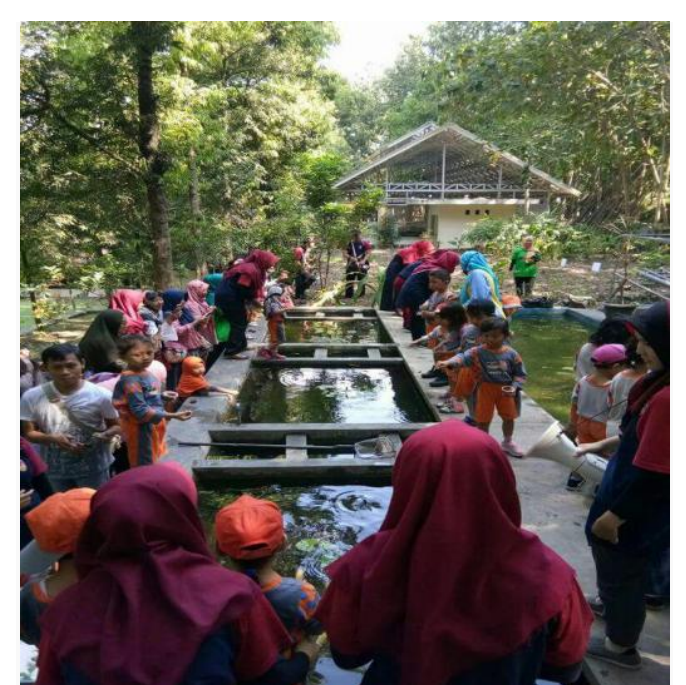

Gambar 7. Pengenalan Budidaya Ikan

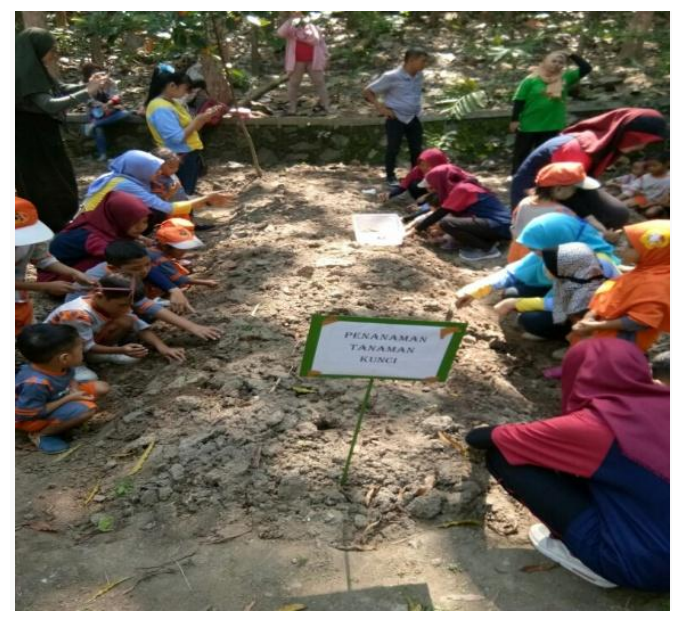

Gambar 8. Penanaman Empon-empon

Peserta didik dari TK Beetle Bug Semarang terlihat antusias berkeliling mulai dari area green house, berfoto dengan kolam ikan hias, memberi makan ikan untuk budidaya, memberi makan ikan untuk budidaya, menanam empon empon, serta mencoba teknologi hidroponik hingga memanen sayur. Kegiatan wisata edukasi pada agroeduwisata ini memiliki tujuan utama untuk memperoleh pengalaman pembelajaran secara langsung di tempat wisata tersebut dalam hal ini adalah UPGRIS Farm

\section{KESIMPULAN}

a. Teknologi "Hidroponic dan Aquaculture" menjadi daya tarik dan bagian dari pengembangan Agroeduwisata UPGRIS-Farm.

b. Pengelolaan yang baik akan menjamin penyelenggaraan kawasan Agroeduwisata yang berfungsi secara maksimal.

\section{SARAN}

Sebagai upaya pengembangan UPGRIS-Farm menjadi kawasan Agroeduwisata yang berfungsi secara maksimal perlu dilakukan kegiatan perencanaan dan pengembangan konsep yang matang terkait jenis edukasi, tata ruang, tata hijau dan fasilitas yang akan diberikan, sehingga pengunjung dapat memetik manfaat serta mendapatkan pelayanan dan kenyamanan yang optimal.

\section{UCAPAN TERIMAKASIH}

Kami ucapkan terimakasih yang setulus-tulusnya kepada Kemenristekdikti, LPPM Universitas PGRI Semarang yang telah memfasilitasi kegiatan PPUPIK Tahun 2018. Tim Pengabdian juga berterimakasih kepada dosen-dosen Progaram Studi Pendidikan Biologi Universitas PGRI Semarang, masyarakat dan mitra yang telah berperan aktif dalam menunjang keberhasilan kegiatan ini. 


\section{DAFTAR PUSTAKA}

Adharani, N., Soewardi, K., Syakti, A. D., \& Hariyadi, S. (2017). Manajemen Kualitas Air Dengan Teknologi Bioflok: Studi Kasus Pemeliharan Ikan Lele (Clarias Sp.). Jurnal Ilmu Pertanian Indonesia, 21(1), 35-40.

Avnimelech, Y. (2009). Biofloc technology. A practical guide book. The World Aquaculture Society, Baton Rouge, 182.

Budiarti, T., \& Muflikhati, I. (2014). Pengembangan Agrowisata Berbasis Masyarakat pada Usahatani Terpadu guna Meningkatkan Kesejahteraan Petani dan Keberlanjutan Sistem Pertanian. Jurnal Ilmu Pertanian Indonesia, 18(3), 200-207.

De Schryver, P., \& Verstraete, W. (2009). Nitrogen removal from aquaculture pond water by heterotrophic nitrogen assimilation in lab-scale sequencing batch reactors. Bioresource Technology, 100(3), 1162-1167.

Ekasari, J. (2009). Bioflocs Technology: Theory and Application in Intensive Aquaculture System. Jurnal
Akuakultur Indonesia. 8(2): 117126

Genuncio, GC., M. Gomes., AC. Ferrari., N. Majerowicz., E. Zonta. (2012). Hydroponic Lettuce Production in Different Concentrations and Flow Rates of Nutrient Solution. Horticultura Brasileira , 30(3), 526530.

Iren, 2007. Cisaga CityAgroeduwisata.

http://ireng84.bravejournal.com. (18:46). 